\title{
A INTERNACIONALIZAÇÃO DO ESTADO NA HISTÓRIA CONTEMPORÂNEA: POSIÇÕES DE UM DEBATE CRÍTICO INTERDISCIPLINAR
}

\section{THE INTERNATIONALIZATION OF THE STATE IN CONTEMPORARY HISTORY: QUESTIONS OF THE CRITICAL INTERDISCIPLINARY DEBATE}

\author{
Rejane Carolina Hoeveler ${ }^{1}$
}

\begin{abstract}
Resumo: $O$ debate acerca da internacionalização do Estado na história contemporânea é interdisciplinar e já se desenvolve desde os anos 1980, renovando-se até hoje, porém, com novas contribuições provenientes de distintas correntes teóricas. As transformações vividas pelo Estado contemporâneo se relacionam tanto com as metamorfoses do capitalismo contemporâneo quanto com as diversas crises que se entrecruzaram ao longo dos anos 1970, a partir das quais se nota um avanço na relevância das organizações internacionais de diversos tipos. No artigo procura-se identificar e debater as proposições das principais correntes críticas que abordaram o problema da internacionalização do Estado, entre elas as dos chamados "neogramscianos" (como Robert Cox e Stephen Gill) e dos "neopoulantzianos" (como Bob Jessop, C. Gorg e U. Brand). Pretende-se problematizar estas classificações, mas ao mesmo tempo identificar as matrizes teóricas comuns a estas correntes, comparando suas hipóteses acerca do problema e também relacionando estudos de caso internacionais de relevância acerca do tema.
\end{abstract}

Palavras-chave: Internacionalização do Estado; neogramscianos; neopoulantzianos

\begin{abstract}
The debate about the internationalization of the state in contemporary history is interdisciplinary and has been developed since the 1980s, renewing itself until today, however, with new contributions from different theoretical perspectives. The transformations experienced by contemporary state relate both to the metamorphosis of contemporary capitalism as with the various crises that crisscrossed over the 1970s, from which we note an improvement in the relevance of international organizations of various kinds. The article seeks to identify and discuss the main propositions of critical currents that have addressed the issue of internationalization of the state, including the so-called "neogramscian" (as Robert Cox and Stephen Gill) and " neopoulantzians " (as Bob Jessop , C . Gorg and U. Brand). In this article we intend to discuss these classifications, but at the same time identify the common features of these current theoretical frameworks, comparing their hypotheses about the problem and also linking relevant international case studies on the theme.
\end{abstract}

Key-words: Internationalization of the State; neogramscian; neopoulantzian

1 Mestranda em História contemporânea do Programa de Pós-Graduação em História da Universidade Federal Fluminense (PPGH/UFF) e bolsista da CAPES. 


\section{Introdução}

É sabido que na disciplina das Relações Internacionais (R.I.) a distinção mais destacada pela literatura é aquela entre "liberais" e "realistas", mas reduzir o rico e heterogêneo debate teórico nas R.I. apenas nestas duas matrizes nos parece um tanto reducionista. O diálogo entre os historiadores e teóricos de R.I. é por vezes muito forte, como podemos notar na influência que teve a obra do historiador Edward H. Carr, Vinte anos de crise. ${ }^{2}$ Em geral, no entanto, o diálogo tem sido menos intenso do que poderia.

Um dos debates mais importantes travados entre autores das Relações Internacionais, cientistas políticos e historiadores nos últimos anos tem a ver com aquilo que se convencionou chamar de "internacionalização do Estado". Seria basicamente o processo através do qual as principais decisões político-econômicas das nações (o chamado policy-making) são cada vez mais influenciadas pelas determinações internacionais. É consenso entre os estudiosos que dos anos 1970 aos dias atuais cresceu exponencialmente a importância de organizações internacionais, públicas e privadas. Mas o seu entrelaçamento entre si e com os Estados Nacionais é motivo de grande controvérsia teórica interdisciplinar. Teriam estas organizações sobrepujado o poder do Estado Nacional? Quais são as transformações pelas quais este Estado passou, e como isto afetou toda a história do último quartel do século $X X$, e deste início de século XXI? Estas tendências vieram pra ficar? Estas são algumas das questões colocadas, que como veremos são respondidas de diferentes maneiras.

O historiador inglês Eric Hobsbawm não deixara escapar o tamanho do problema, destacando em sua Era dos Extremos a multiplicação de organizações internacionais de variados tipos nas décadas de 1970 e 1980. Em suas palavras,

"Quando a economia transnacional estabeleceu seu domínio sobre o mundo, solapou uma grande instituição, até 1945 praticamente universal: o Estado-nação territorial, pois um Estado assim já não poderia controlar mais que uma parte cada vez menor de seus assuntos. Organizações cujo campo

2 CARR, E.H. Vinte anos de crise (1919-1939). Uma Introdução ao Estudo das Relações Internacionais. $2^{a}$ Edição. Brasília: Ed. UNB (Instituto de Pesquisas de Relações Internacionais); São Paulo: Imprensa Oficial do Estado de São Paulo, 2001. 
de ação era efetivamente limitado pelas fronteiras de seu território, como sindicatos, parlamentos e sistemas públicos de rádio e televisão nacionais, saíram portanto perdendo, enquanto organizações não limitadas desse jeito, como empresas transnacionais, o mercado de moeda internacional e os meios de comunicação da era do satélite, saíram ganhando. O desaparecimento das superpotências, que podiam de qualquer modo controlar os Estados-satélites, iria reforçar essa tendência." ${ }^{3}$

$\mathrm{Na}$ verdade, tornou-se quase um lugar comum a noção de que teria havido um processo de solapamento das bases dos Estados Nacionais, algo em grande parte difundido pela chamada "ideologia da globalização" - nesta, algo visto como intrinsecamente positivo, já que o Estado, nessa visão, é encarado como algo anacrônico, ultrapassado, e que precisa ser constantemente liberado das correntes que regulam os mercados globais, especialmente o de investimentos. Por outro lado, alguns estudiosos que se contrapõem frontalmente a esta ideologia têm procurado demonstrar o quanto os Estados Nacionais ainda cumprem papéis absolutamente fundamentais, e que não pode existir sistema capitalista sem Estado. Veremos como as posições que vão nesse sentido procuram compreender as inegáveis transformações nos Estados neste período.

É difícil enquadrar o debate acerca da internacionalização dos Estados em escolas muito coesas e identificadas. O termo foi cunhado pelo conhecido teórico canadense Robert Cox, mas como veremos adiante, nem mesmo em sua obra fica muito claro o que se quer dizer com o conceito, embora seus insights tenham contribuído significativamente para a renovação das abordagens críticas dentro das Relações Internacionais. Por outro lado, é comum que autores de matrizes teóricointerpretativas completamente diferentes se utilizem dele, também para falar de coisas completamente diferentes.

Susan Strange, por exemplo, importante teórica da chamada Economia Política Internacional (E.P.I), e autora de importantes trabalhos acerca do que ela chama de "capitalismo de cassino" dos anos 1980 para cá, também versou sobre o

3 HOBSBAWN, Eric. Era dos Extremos. O breve século XX (1914-1991). São Paulo, Companhia das Letras, 1995. p. 413. "A simples necessidade de coordenação global multiplicou as organizações internacionais mais rápido do que nunca nas Décadas de Crise [1970 e 1980]. Em meados da década de 1980, havia 365 organizações intergovernamentais e nada menos que 4615 não-governamentais, ou seja, acima de duas vezes mais que no início da década de 1970." Idem, p. 419. 
tema, mas chegou a conclusões distintas. Em um pequeno artigo intitulado "As supranacionais e o Estado", 4 Strange afirma existir um paradoxo no fato de que enquanto a economia se tornou mais entrelaçada e os meios de transporte e comunicação mais baratos e eficientes, dando início a uma "sociedade mundial", o sistema político internacional (no sentido de interestatal) teria se mantido basicamente inalterado. Segundo Strange, "enquanto a autoridade do Estado tem-se encontrado sob ataque proveniente de dois campos diferentes, decorrente de dois tipos distintos de entidades supranacionais ou transnacionais, ao mesmo tempo ambas as entidades têm, também, contribuído ativamente em prol do poder e autoridade do Estado." Para a autora, no entanto, a questão giraria apenas em torno do "aumento" ou "diminuição" do Estado, o que nos parece deixar lacunas importantes em sua problematização.

Segundo Fred Halliday, o debate nas R.I. desde os anos 1970 sobre Estado se dividiria basicamente entre aqueles que defendem a primazia do Estado como ator central das R.I. e aqueles que defendem a emergência de novos atores, nãoestatais. Do primeiro grupo, seriam representantes os "realistas", e do segundo, os "transnacionalistas", mas em ambos predomina a abordagem do Estado "caixapreta", isto é, de uma entidade quase que indecifrável. As R.I., segundo o autor, passariam assim ao largo de todo o debate sociológico acerca dos determinantes sociais do Estado, ignorando quase que absolutamente as diversas proposições marxistas a este respeito. ${ }^{6}$

De toda forma, na contracorrente das posições hegemônicas nas R.I., Strange e Halliday apontam para algo que nos parece incontornável: a centralidade das transformações capitalistas no período em tela. Sem uma teoria do capitalismo capaz de abranger suas metamorfoses mais recentes, como a crescente importância das corporações multinacionais a partir do segundo pós-guerra, tende-se a cair em visões pouco críticas ou com fraca teorização.

$4 \quad$ Publicado edição brasileira do livro organizado por HALL, John. Os Estados na História. Rio de Janeiro: Imago, 1992.

5 STRANGE, S. "As supranacionais e o Estado", In. HALL, J. (org.), Op. Cit., p. 423.

6 HALLIDAY, Fred. Repensando as relações internacionais. Porto Alegre: EdUFRGS, 1999. Conferir também como o tema foi discutido pelo próprio Cox, em: BORBA DE SÁ, Miguel; GARCIA, Ana S. ; COX, Robert W. "Overcoming the Blockage: an interview with Robert W. Cox". Estudos Internacionais: revista de relações internacionais, v. 1, p. 119-336, 2013. 
Por esse motivo nosso intuito aqui é focalizar justamente como estas posições mais críticas, dentro ou fora do marxismo, têm tratado do assunto. Chamamos a atenção para a diversidade de interpretações possíveis acerca do assunto, lembrando que aqui estamos levantando aquelas que consideramos mais relevantes para o entendimento do problema.

Este trabalho está assim dividido em três partes, ambas centradas na apresentação dos contornos de cada uma das três correntes relativamente consolidadas com relação ao debate da internacionalização do Estado. Começaremos por aqueles autores que, já desde os anos 1980, forneceram contribuição inestimável à renovação crítica nas R.I., a partir do pensamento que ficou conhecido como "neogramsciano". Ao abordar essa corrente, procuraremos retomar a teoria política do filósofo sardo Antônio Gramsci a partir da qual tais autores constituíram suas hipóteses, além das diferenças parte discorreremos brevemente acerca da corrente um pouco mais recente que vem a ser conhecida como "neopoulantziana", por conta de sua referência central na obra do politólogo greco-francês Nicos Poulantzas. Aqui caberá mencionar dois importantes estudos de caso realizados acerca da internacionalização do Estado em dois importantes episódios: a tentativa fracassada do Multilateral Agreement of Investment (MAI), e a Convenção sobre a Diversidade Biológica, realizada no contexto da "Rio 92". Consideramos que tais estudos fornecem valioso "chão empírico" a partir do qual refletir acerca da internacionalização do Estado nas proposições desta corrente teórica. $\mathrm{Na}$ terceira parte, discutiremos a contribuição de outra matriz, proveniente do rico debate alemão acerca do Estado nos anos 1970, e que construiu sua teoria a partir de um debate com o chamado pensamento regulacionista francês abordaremos especificamente o pensamento de Joaquim Hirsch acerca da internacionalização do Estado. Por fim, teceremos algumas considerações finais acerca das perspectivas colocadas em relação ao tema hoje.

\section{Gramsci e os "neogramscianos"}

Comecemos, pois, pelos principais introdutores do conceito de “internacionalização do Estado". É hoje muito difundida a idéia de que as pesquisas 
relacionadas ao trabalho de Antonio Gramsci tornaram possíveis inegáveis insights conceitual-teóricos e empíricos, porém com uma fragilidade teórica geral em relação ao tema do Estado. Muito embora as reflexões da chamada escola "neogramsciana" estejam voltadas para debates internos às disciplinas de Relações Internacionais (R.I.) e de Economia Política Internacional (E.P.I.) - principalmente porque seu impulso inicial foi o de promover uma crítica ao paradigma neo-realista então predominante nas R.I. - as análises empenhadas por ela podem ser incorporadas pelos estudiosos do capitalismo contemporâneo e da História Contemporânea em geral.

Em primeiro lugar é necessário definir o que está sendo denominado de "escola neogramsciana", definição que por si só já carrega controvérsias, já que alguns dos autores que são assim chamados negam tal classificação. Ficaremos, para sintetizar, com a definição apresentada por Julian Saurin, ${ }^{7}$ que delimita a escola neogramsciana como composta por acadêmicos basicamente de R.I. e de E.P.I., que fazem sistematicamente o uso de Gramsci em suas análises, de 1981 para cá - a data se refere à publicação do artigo seminal de Robert Cox (considerado o fundador da escola) na Revista Millenium, "Social Forces, States and World Orders". Estamos falando de nomes como Kees van der Pijl, Stephen Gill, Mark Rupert, Craig Murphy, David Law, Barry Gills, Otto Holman e Enrico Augelli, entre outros (Giovanni Arrighi é considerado como um colaborador, embora apresente, em nossa opinião, problemática muito distinta; Adam Norton também é um caso excepcional em sua relação com a "escola"). ${ }^{9}$ Todos esses nomes mereceriam análises à parte; porém, para atender os objetivos aqui almejados, nos restringiremos a dois grandes representantes de peso: o próprio Robert Cox e Stephen Gill, que é considerado,

7 SAURIN, Julian. "The formation of Neo-Gramscians in International Relations and International Political Economy: neither Gramsci nor Marx". In. AYERS, Alison J. (ed.) Gramsci, Political Economy, and International Relations. Modern Princes and Naked Emperors. New York: Palgrave-Macmillan, 2008. p. 23-44.

8 COX, Robert. "Social Forces, States and World Orders: Beyond International Relations Theory." Millennium: Journal of International Studies, v. 10, n.2, 126-155, 1981.

9 Preferiremos não adotar a denominação "nova escola italiana", por sua total imprecisão, já que apenas um italiano, Enrico Augelli, pode efetivamente ser considerado parte desta perspectiva. A Universidade de York, em Toronto, no Canadá, é mais significativa em termos de membros (Cox e Gill), mas a "corrente" também tem presença na Escola de Relações Internacionais de Amsterdã e em diversas outras universidades britânicas e norte-americanas, como Newcastle, Sussex, Siracusa, entre outras. 
depois de Cox, uma das maiores referências da "escola". ${ }^{10}$

A partir da matriz gramsciana, "intelectual orgânico" é entendido como aquele vinculado a um projeto político de classe ou fração de classe; "hegemonia" trata da forma de dominação social baseada numa relação equilibrada entre coerção e consenso; e "bloco histórico" é a ligação orgânica entre a estrutura e superestrutura, ou seja, uma relação dialeticamente determinada entre o Estado (entendido num sentido amplo, e não apenas de aparelho estatal) e as formas da produção social (que inclui formas ideológicas e culturais).

Hoje são conhecidas as passagens nas quais Gramsci se colocava questões da relação de forças a nível internacional (Caderno 13, § 2); ou nas quais aplicava ao nível internacional sua famosa distinção entre "grande política" ("questões relacionadas com a estrutura relativa de cada Estado nos confrontos recíprocos") e "pequena política" (por exemplo "questões diplomáticas que surgem no interior de um equilíbrio já constituído e que não tentam superar aquele equilíbrio para criar novas relações"). ${ }^{11}$

Alguns autores, como Julian Saurin, defendem a impossibilidade de aplicar o conceito de hegemonia à esfera internacional, com o argumento de que o conceito de hegemonia em Gramsci é intimamente ligado ao de Estado, que é, por sua vez, Estado Nacional. ${ }^{12}$ Porém, se considerarmos a definição de hegemonia prioritariamente como a relação (não dicotômica e nem binária) entre coerção e consenso, torna-se, em nossa opinião, perfeitamente possível, com as devidas precauções teóricas, utilizar este conceito para analisar a situação internacional.

Criticando fortemente tanto o paradigma do neorealismo, predominante nos estudos sobre as relações internacionais, quanto o que chamaram de um marxismo "economicista" e "determinista", os neogramscianos chamaram a atenção para o papel de instituições, aparelhos privados de hegemonia e de intelectuais orgânicos

10 Para uma discussão crítica no Brasil, ver os trabalhos do cientista político Rodrigo Passos, por exemplo: PASSOS, Rodrigo D. F. "Gramsci e a teoria crítica das relações internacionais". In Revista Novos Rumos, Vol. 50, No 2, 2013. Disponível em: http://www2.marilia.unesp.br/revistas/index.php/novosrumos/article/viewFile/3462/2681. (acessado em 20 de novembro de 2013).

11 GRAMSCI, Antonio. Cadernos do Cárcere. Rio de Janeiro: Civilização Brasileira, 2007. Vol. 3, p.22.

12 SAURIN, J, Op. Cit. 
na (re)construção da hegemonia americana e na constituição do cenário para a aplicação das políticas neoliberais, em meio à crise do keynesianismo, nos anos 1970.

Como já nos referimos, foi $\operatorname{Cox}^{13}$ quem primeiro introduziu o conceito de internacionalização do Estado: por um lado, sob a liderança de um Estado hegemônico globalmente ou de uma aliança de forças políticas e econômicas, certas responsabilidades atribuídas ao Estado seriam externalizadas e redefinidas dentro da estrutura de regimes internacionais. Por outro, essas mudanças envolvem uma reorganização da regulação nacional-estatal, desde que, em vista das mudanças das relações de poder, as relações de peso mútuas entre Estados particulares teriam se modificado.

Cox identifica basicamente três componentes da internacionalização do Estado. Primeiro, existiria um processo de formação de consenso interestatal com relação às necessidades ou condições da economia mundial que toma lugar dentro de uma estrutura ideológica comum. Segundo, a participação nesse consenso seria hierarquicamente estruturada. Terceiro, as estruturas internas de Estados seriam ajustadas de forma que cada uma possa transformar melhor o consenso global em política e prática nacional. Para Cox a internacionalização do Estado é definida então pela conversão do Estado em uma agência para ajustar as práticas e políticas econômicas nacionais às exigências percebidas da economia global. Esta noção joga luz sobre a profunda articulação contemporânea entre as instituições e determinações do capital transnacional, em especial a forma como é elaborada e posta em prática a policy-making dos Estados Nacionais, ressaltando os mecanismos pelos quais as tomadas de decisão macroeconômicas dos Estados são construídas internacionalmente, pelas elites dominantes. ${ }^{14}$

13 COX, Robert. Production, Power and World Order: Social Forces in the Making of History. New York: Columbia University Press, 1987.

14 Segundo o cientista político Alvaro Bianchi, "sua aproximação [de Cox] de Gramsci destacase na medida em que sua apropriação do conceito de hegemonia lhe permite compreender não apenas a hegemonia de uma nação sobre outras, como também a de uma classe ou fração sobre outras. Para tanto evita a redução do conceito à esfera da ideologia, articulando as dimensões sociais, econômicas e político-ideológicas da vida social". BIANCHI, A. "Estratégia do contratempo: notas para uma pesquisa sobre o conceito gramsciano de hegemonia". In. Cadernos Cemarx,

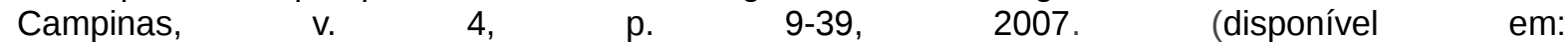
http://www.ifch.unicamp.br/ojs/index.php/cemarx/article/viewFile/1278/856). (acessado em $13 \mathrm{de}$ agosto de 2012). 
Uma ideia central presente em Cox, e que foi seguida por autores como o teórico Stephen Gill, é que, a partir de meados dos anos 1960, teria se constituído uma fração de classe capitalista transnacional, composta pelos setores mais internacionalizados do capital, especialmente aqueles ligados às finanças. Esta fração teria dado suporte (com o trabalho de suas organizações, aparelhos e intelectuais) a um bloco histórico transnacional. Este bloco histórico transnacional teria sido construído ao longo dos anos 1970, concomitantemente à crise do "bloco histórico internacional" que teria caracterizado o segundo pós-guerra (para Cox, um mix de socialdemocracia, compromisso de classe em uma "economia mista" baseada na acumulação fordista, e comércio internacional crescente, sob a liderança dos EUA, entre os anos 1940 e 1950, e que teria durado até pelo menos o fim dos anos 1960). ${ }^{15}$

O sociólogo norte-americano William I. Robinson, também tributário da noção de uma "classe capitalista transnacional", afirma claramente que a internacionalização do Estado converte Estados-Nação em "correias de transmissão" e "dispositivos de filtragem" (filtering devices) para a imposição da "agenda transnacional"; e que a função do Estado estaria mudando da formulação de políticas nacionais para a administração de políticas formuladas por essa elite transnacional atuante através de instituições supranacionais. Neste papel, o EstadoNação contribuiria para a acumulação global de capital de várias formas: adotando a política fiscal e monetária necessária para manter estabilidade econômica, criando infraestrutura básica para a atividade econômica global, e provendo controle e estabilidade social. ${ }^{16}$

Em contraste com o período do capitalismo fordista, a hegemonia não seria mais exercida por um único Estado-Nação, os EUA. Na era "pós-fordista", a

15 De acordo com Gill, o conceito gramsciano de bloco histórico refere-se àquelas situações em que existe um alto grau de congruência política entre as relações de força, dentro das quais existem três níveis de consciência, o econômico-corporativo, o da solidariedade de interesses e o político-militar. Encontramos em Gill a definição mais precisa de que o bloco histórico é, para Gramsci, o link orgânico entre a estrutura e a superestrutura (ao contrário, por exemplo, da interpretação de Portelli, que define o bloco histórico como um "bloco de alianças"). GILL, American Hegemony and the Trilateral Commission. Cambridge: Cambridge University Press, 1990. p. 45. Bianchi identifica a origem desse último equívoco em: BIANCHI, A. O laboratório de Gramsci. Filosofia, História e Política. São Paulo: Alameda, 2008. p.137-138.

16 ROBINSON, W. "Gramsci and globalization": from nation-state to transnational hegemony. In. BIELER \& MORTON (eds.). Images of Gramsci. London/New York: Routledge, 2006. 
transformação neoliberal das sociedades nacionais e do sistema internacional teria se tornado a estrutura ideológica dominante para as regulações políticas culminando no famoso "consenso de Washington" de 1989 - através de uma rede internacional, a "classe gerencial transnacional".

Em geral, no entanto, o conceito de internacionalização do Estado permanece um tanto vago. O próprio Cox define o processo como "nebuloso", como uma constelação que emergiu de dentro de uma nebulosidade ideológica, na qual as elites estão crescentemente orientando seus pensamentos e comportamento para o mercado mundial. Então, de acordo com esta tendência, o Estado é basicamente interpretado no sentido de um sistema político-institucional que opera como uma correia de transmissão das constelações de poder internacional dentro das sociedades nacionais.

A partir daí, teria se constituído algo como uma "sociedade civil internacional", uma rede ligada por instituições orgânicas e que atua politicamente dentro (mas para além) dos âmbitos nacionais. Para Cox, seria possível localizar também indícios da constituição de uma sociedade política internacional. A crise da hegemonia americana nos anos 1960 e 1970, segundo o autor, teria provocado a necessidade de uma nova e modificada estrutura institucional, que se refletiu no esforço de organização de fóruns como a Trilateral Commission ou os Western Economic Summit Meetings. Essa "crise de hegemonia" (novamente é explícita a referência a Gramsci) teria gerado a busca pela construção de um novo consenso hegemônico, que teria que refletir necessariamente não apenas o peso da Alemanha e do Japão, mas também o crescimento do capital transnacional, assim como levar em conta a ascensão de certas nações recentemente industrializadas. ${ }^{17}$

O seminal trabalho de Stephen Gill sobre a Trilateral Commission trouxe uma série de questões para a elucidação da atuação política internacional desse denominado "capital transnacional". Gill dedica grande parte de seu estudo a refutar

$17 \quad \mathrm{Na}$ análise de Gill, a profunda recessão do fim dos anos 1970 e início dos anos 1980 paradoxalmente facilitou a retomada da hegemonia americana, pois embora ela tenha sido mais forte nos próprios EUA, sua capacidade de recuperação era maior. A metáfora gramsciana de "aliança orgânica" (estrutural) - entre EUA, Europa Ocidental e Japão - ajudaria a explicar a firmeza do Império americano dos anos 1970 para cá. GILL, Stephen. Op. Cit. Sobre o trilateralismo, ver também a contribuição pioneira da cientista política norte-americana Holly Sklar: SKLAR, Holly (org.) Trilateralism: managing dependence and democracy. Boston: South and Press, 1980. 
o mito do fim da hegemonia americana, ideia que contaminou boa parte das visões marxistas durante os anos 1970, e que foi predominante entre os neo-realistas. Nesta argumentação, ele critica, com base em Robert Brenner, a perspectiva dos adeptos do "sistema-mundo" (principalmente em Immanuel Wallerstein e Giovanni Arrighi), por entenderem a hegemonia como algo cíclico e que já estaria numa fase de inevitável decomposição. De acordo com Gill, nos anos 1970 houve uma crise de hegemonia internacional, a qual teria envolvido uma transformação estrutural na natureza da ordem político-econômica do pós-guerra, e que não foi apenas decorrente da crise econômica. Aplicando as categorias gramscianas às relações internacionais, o autor concluiu que a Trilateral Commission representava, do ponto de vista da burguesia internacional, o estágio mais avançado de sua "consciência de classe", já em seu momento propriamente político (e não apenas econômicocorporativo ou de solidariedade de interesses, na diferenciação de Gramsci) ${ }^{18}$. Por este motivo, esta entidade privada teria cumprido o papel de liderança na formação de um novo bloco histórico mundial, atuando como verdadeiro "partido" desta fração de classe, não apenas produzindo ideologias, mas organizando a hegemonia desta fração. ${ }^{19}$

Como vimos até agora, ainda que nos restringindo a apenas alguns autores, a chamada escola neogramsciana trouxe aportes teóricos consideráveis para a análise das relações interestatais na história contemporânea, e contribuiu também com estudos empíricos de relevância para embasar suas hipóteses. Vejamos agora como argumentam os críticos dessa escola.

De acordo com o cientista político "neopoulantziano" C. Gorg, as insuficiências da abordagem neogramsciana estariam pelo menos em três noções: primeiro, na definição de "forças sociais"; segundo, na definição de Estado; e terceiro, em relação às relações recíprocas entre os espaços nacionais. Para Gorg,

18 GRAMSCI, Op. Cit., §17, Caderno 13.

19 GILL, Stephen. Op. Cit.. A Trilateral Commission começou a ser formulada já nos extertores da década de 1960, porém só seria formalmente fundada em 1973, a partir de quando foi se consolidando como uma das iniciativas mais bem sucedidas de organização de interesses do capital transnacional, tendo como primeiro grande balanço político a eleição de "Jimmy" Carter para a presidência dos EUA, em 1976. Reunia mais de 200 consórcios capitalistas de várias partes do mundo e tinha significativa inserção em alguns importantes meios acadêmicos nos EUA, Inglaterra, Alemanha Ocidental e Japão. Ela era a diretamente ligada ao "projeto anos 80" do famoso Council of Foreign Relations (CFR). 
um importante insight de Gramsci é que, primeiramente, a dominação não pode ser entendida somente como uma estratégia de sucesso e a produção do consenso de cima, mas também como uma relação social abrangente e, também, como relação de forças. ${ }^{20}$

Segundo, para Gorg, a fixação das abordagens neogramscianas com os processos na sociedade civil efetivamente significa que as classes são analiticamente privilegiadas em relação aos Estados. Consequentemente, os trabalhos neogramscianos seriam caracterizados por um "duplo funcionalismo" com relação ao Estado. Por um lado, a internacionalização do Estado seria interpretada como um complemento à internacionalização da produção, a qual, como Cox argumenta, representa acima de tudo um consenso ideológico assim como uma forma institucional coerente. Por outro lado, as instituições políticas internacionais e organizações são vistas mais ou menos como "instrumentos" das classes dominantes e suas estratégias.

Argumenta-se também que a introdução da política neoliberal no nível nacional não foi sempre conseqüência da formulação de um consenso internacional mas em si um pré-requisito e um importante fundamento deste consenso. Quando Cox mesmo chamou este consenso de algo "nebuloso", a razão para este problema empírico seria que a transformação do Estado-Nação era na verdade uma précondição necessária ao consenso internacional. Esta transformação teria incluído pelo menos dois pontos: novos compromissos sociais e de classe no nível nacional, moldando política nacional em direção ao livre mercado, e modificações nas relações de poder entre diferentes elementos do aparelho de Estado, especialmente pelo poder crescente dos bancos centrais e dos ministérios de finanças dos países.

Nesta interpretação crítica, Cox e cia. teriam assim caído num dos "mitos da globalização" - em especial, a noção de que ela é algo de fora das economias

20 GORG, C. "The internationalization of the State and the example of biological diversity". In. GORG, C \& BRAND, U. Global environmental politics and competition between nation-states. On the regulation of biological diversity. In: Review of International Political Economy v.7, n.3, p.371-398, 2000. Segundo Ana Garcia, haveria uma coisa em comum a Cox a Poulantzas, que seria "uma distinção subjacente entre natureza do Estado, formas de Estado e função do Estado". GARCIA, Ana Saggioro. A internacionalização de empresas brasileiras durante o governo Lula: uma análise crítica da relação entre capital e Estado no Brasil contemporâneo. Tese de doutorado em Relações Internacionais - IBRI. Pontifícia Universidade Católica do Rio de Janeiro, 2012.p.183. 
nacionais trabalhando apenas como uma coerção externa. Na verdade, a globalização não seria algo de fora das fronteiras nacionais - como aparentaria apenas da perspectiva de cada Estado-Nação - mas algo que é produzido por uma transformação societal dentro das sociedades nacionais, uma transformação societal que em sua visão é interpretada como a transição do fordismo ao pós-fordismo.

Para Gorg, seguindo aqui Gramsci, a hegemonia não pode ser reduzida ao exercício do poder ou dominação. Como hegemonia tem a ver com a habilidade de orientação política ela inclui também a habilidade de compromisso e de levar diferentes interesses em consideração; dentro de cada país e a nível internacional, não apenas ideologicamente, mas também materialmente. ${ }^{21}$ (Esta habilidade para o compromisso estaria cada vez mais fora da perspectiva do governo dos EUA, especialmente depois de 2001, e por isso estaríamos presenciando, hoje, uma nova crise de hegemonia internacional).

Segundo Pinar Bedirhanoglu ${ }^{22}$, a proposta de Cox acerca da "internacionalização do Estado" foi criticada tanto por representantes da corrente conhecida como Open Marxism ${ }^{23}$, quanto por marxistas influenciados por outras tradições (como a de Polantzas e Miliband), especialmente pelo também canadense Leo Panitch.

Panitch também critica a subestimação do Estado e a forma "de fora pra dentro" de pensar este fenômeno, na qual processos internacionais têm efeitos nos processos nacionais, tornando o Estado uma correia de transmissão passiva ou numa espécie de "vítima" de processos internacionais. Desta forma, o autor procura

21 Na visão de Gorg, a teoria de Poulantzas não poderia ser diretamente conectada com a de Gramsci, já que o primeiro subestima a importância da sociedade civil, no sentido de autoorganização social, concentrando-se mais no aparelho do Estado. Mesmo com todas as críticas, no entanto, Gorg não nega a existência de uma sociedade civil internacional, mas alega que uma transposição produtiva da noção gramsciana de sociedade civil pressuporia o entendimento de uma sociedade (global), e de fato, a sociedade civil internacional não seria um setor intermediário, mas uma relação internacional de forças societais. Como o terreno onde a hegemonia é disputada, a sociedade civil internacional seria ao mesmo tempo o objeto e o meio da luta. GORG, Op. Cit.

22 BEDIRHANOGLOU, P. "The State in neoliberal globalization: the merits and limits of Coxian conceptions". In. AYERS, Alison J. (ed.), Op. Cit.

23 Grupo que se reuniu em torno das revistas Arguments (1958-62); Common Sense (198799), e The Commoner (criada em 2001). O grupo tinha influências diversas como Isaac Rubin até autores do chamado "marxismo autonomista"; nos anos 1970 e 1980 os open marxists debateram as teses "derivacionistas" no grupo Kapitalistate, baseado em São Francisco, EUA. Alguns nomes associados ao Open Marxism são John Holloway, Simon Clarke e Peter Brunham. 
reiterar o papel central e constitutivo dos Estados no capitalismo com base em sua função, atribuída por Poulantzas, de mediação entre os interesses conflitantes das distintas frações do capital. A intervenção metodológica de Panitch redefiniu o Estado como uma fonte da mudança em si, isto é, um sujeito da mudança (a serviço dos interesses e diretamente, pelas próprias classes dominantes), e não apenas, como aparece em Cox, um objeto desta.

Nas palavras de Panitch,

a realização - ou frustração - das tendências globalizantes do capitalismo não pode ser compreendida independentemente do papel exercido pelos Estados que historicamente constituíram o mundo capitalista. ${ }^{24}$

De acordo com Panitch, o que teria acontecido nos anos 1970 seria que os Estados da Europa, dos EUA e do Japão teriam aceitado a responsabilidade de criar as condições internas necessárias para sustentar a acumulação mundial; não estavam portanto desaparecendo, mas "somando responsabilidades". ${ }^{25}$ Desde então, o papel dos Estados em relação às crises não é mais preveni-las e sim contêlas dentro de certos limites. Neste ponto o papel do Estado norte-americano teria demonstrado enorme capacidade em limitar a duração, a profundidade e o contágio das crises.

Panitch incorpora a expressão internacionalização do Estado, mas com algumas ressalvas.

Como parte da diferenciação entre as esferas econômica e política,
capitalistas particulares estenderam seu alcance de atividades para além
das fronteiras territoriais de seus respectivos Estados. Enquanto os Estados
freqüentemente encorajaram e deram suporte aos capitalistas para fazer
isso, existiu sempre uma dimensão especificamente nacional no processo
de internacionalização capitalista. E conforme a interação com o capital
externo afetava as forças sociais domésticas, isso em troca contribuiu para
gerar a combinação de pressões internas e externas através das quais os
Estados passaram a aceitar uma certa responsabilidade pela reprodução do

24 PANITCH, L. "Capitalismo global e Império norte-americano". In Socialist Register em

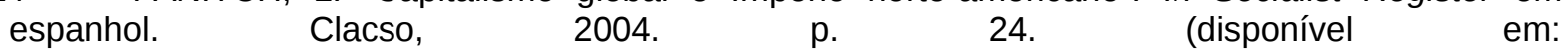
http://bibliotecavirtual.clacso.org.ar/ar/libros/social/2004pt/03_panich.pdf) (acessado em 09 de dezembro de 2013).

$25 \quad$ PANITCH, Op. Cit., p. 43. 
capitalismo internacionalmente. (...) é basicamente neste sentido que podemos propriamente falar da 'internacionalização do Estado'. ${ }^{26}$

Como se vê, Panitch e Gorg desenvolvem uma abordagem bastante crítica às proposições dos chamados "neogramscianos", e o fazem a partir de uma perspectiva poulantziana, a qual discutiremos a partir de agora. ${ }^{27}$

\section{Poulantzas e os "neopoulantzianos"}

É num pequeno artigo denominado "The internalization of capitalist relations and the Nation-State" que Poulantzas desenvolvera alguns pontos que nos interessam diretamente no debate da "internacionalização" do Estado. ${ }^{28}$

Cabe notar antes de tudo que, para o autor, o que caracteriza a produção na atual fase do imperialismo (estamos falando de início dos anos 1970) seria a constituição, sob uma mesma propriedade econômica, "real" (a qual ele distingue da "propriedade legal formal"), de um complexo de unidades de produção com processos de trabalho integrados através de vários estabelecimentos espalhados por vários países. ${ }^{29}$ Muito embora a interpenetração de capitais fosse desde o início uma tendência do estágio imperialista, somente agora ela teria dado um salto qualitativo, configurando uma verdadeira internacionalização do capital. Essa internacionalização do capital seria marcada: 1. Pelo desenvolvimento de bases de exploração de um capital particular (ou de vários capitais em combinação) em diversas nações; e 2. Pela tendência à combinação, sob uma única propriedade econômica, de capitais provenientes de diferentes países; e 3. Pela dominância decisiva do capital norte-americano. ${ }^{30}$

Segundo Poulantzas,

26 PANITCH \&GINDIN. The making of global capitalism. The Political Economy of American Empire. London/New York: Verso, 2012. p. 4. Tradução livre.

27 Para outras interpretações críticas, ver AYERS, Alison J. (ed.) Op. Cit.

28 POULANTZAS, Nicos. "The internationalization of capitalist relations and the Nation-State".

In. Economy and Society. vol. 3 (1974), pp. 145-79. (Disponível em The Poulantzas Reader:

http://ouleft.org/wp-content/uploads/Poulantzas_Reader_Marxism,.pdf) (acessado em 27 de outubro de 2013) Por limitações de espaço, não discutiremos como Poulantzas teorizou sobre o Estado ao longo de sua obra. Cabe, no entanto, marcar que sua concepção do Estado sempre se pautou por uma idéia de "autonomia relativa" do Estado perante as classes dominantes. Ver POULANTZAS, Nicos. O Estado, o poder, o socialismo. Rio de Janeiro: Graal, 2000.

29 Idem, p.233.

$30 \quad$ Idem, p. 234. 


\begin{abstract}
"A corrente internacionalização do capital nem suprime nem curto-circuita os Estados nacionais, nem no sentido de uma integração pacífica de capitais 'sobre' os Estados, com cada processo de internacionalização trabalhando sob a dominância de determinado país (...). Mas, de outro ângulo, essa internacionalização tem um profundo efeito nas formas políticas e institucionais destes Estados por sua inclusão num sistema de interconexões as quais não estão de forma alguma limitadas à interação de pressões 'exteriores' e 'recíprocas' entre Estados e capitais justapostos. Os Estados mesmos assumem responsabilidade pelos interesses do capital imperialista dominante em seu desenvolvimento estendido verdadeiramente dentro da formação 'nacional' (...). Este sistema de interconexões não tende à constituição de formas ou instâncias 'supra-nacionais' ou 'super-estatais'. Isto pode ser o caso se isto fosse uma questão de uma internacionalização num contexto de Estados justapostos com relações externas que teriam que ser suplantadas. Ao contrário, o sistema é fundado em uma reprodução induzida da forma do poder imperialista dominante em cada formação nacional e seu próprio Estado." ${ }^{11}$
\end{abstract}

Para Poulantzas, os Estados engajar-se-iam em assumir a responsabilidade pelos interesses do capital dominante de forma direta, através de subsídios públicos diretos e indiretos. A forma correntemente dominante de contradições interimperialistas não seria aquela entre "capital internacional" e "capital nacional", nem entre burguesias imperialistas entendidas como entidades justapostas.

Ora, argumenta Poulantzas, se o Estado existente das metrópoles imperialistas é modificado na medida em que retrai sua natureza enquanto um Estado nacional, isso seria, do mesmo modo, devido ao fato de que o Estado não é uma mera ferramenta ou instrumento das classes dominantes, a ser "manipulado" à vontade, com todo o estágio da internacionalização do Estado automaticamente provocando uma "supranacionalização" de Estados. O Estado, enquanto aparato de unidade de uma formação e de reprodução de suas relações sociais, concentra e compendia as contradições de classe da formação social como um todo, ao sancionar e legitimar os interesses das classes e frações dominantes em face de outras classes da formação, ao mesmo tempo em que assume as contradições de classe mundiais.

Para Poulantzas, a relação Estado-Nação é mantida porque a nação conservaria sua própria existência com respeito às formas nacionais da luta de classes em toda a complexidade de sua determinação - uma unidade econômica, 
territorial, lingüística, simbólico-ideológica ligada a uma "tradição". Dito isto, entretanto, o autor nota algumas distensões manifestadas entre Estado e Nação, mas não no sentido geralmente dito pela tese da "supranacionalização" do Estado. Em suas palavras,

\begin{abstract}
"Não é a emergência de um novo Estado sobre as nações que estamos testemunhando mas sim rupturas na unidade nacional subjacente aos Estados nacionais existentes. Fenômeno do regionalismo e ressurgimento de nacionalidades mostram que a internacionalização do capital traz à tona cisões na nação tal como historicamente constituída, mais do que a supranacionalização do Estado". ${ }^{32}$
\end{abstract}

Determinar uma "fragilidade" dos Estados perante as "gigantes multinacionais" seria, portanto, falhar em reconhecer não apenas que o Estado não possui poder próprio mas também que ele intervém nessa concentração de maneira decisiva. A dominância do Estado corresponderia ao crescimento considerável das funções econômicas do Estado que são absolutamente indispensáveis à reprodução ampliada do grande capital.

Vejamos agora como os estudiosos hoje conhecidos como "neopoulantzianos" se utilizam desse arcabouço conceitual, em distintas interpretações.

Professor da Universidade de Viena, Ulrich Brand é autor de tese segundo a qual a internacionalização do Estado é uma forma de reconstituição da hegemonia. ${ }^{33}$ Segundo ele, na crise do modelo fordista de desenvolvimento durante os anos 1970, esta internacionalização, com diversas facetas, se tornou a estratégia hegemônica e o projeto hegemônico da burguesia nos centros capitalistas. A globalização do capitalismo é, então, não somente um processo econômico, mas está intimamente ligado aos desenvolvimentos político-institucionais.

Isso significaria primeiramente o crescimento, a nível internacional, da importância de um "aparato de Estado" internacional; e isto se refere àqueles já existiam previamente (Banco Mundial, FMI, OTAN, e União Européia), a outros que foram remodelados (do Gatt ao WTO), e também aqueles que apenas foram criados recentemente (por exemplo, acordos ambientais). Isso não quer dizer, entretanto, a 32 Idem, p. 250-251. Tradução livre.

33 BRAND, U. "The internationalization of the state as the reconstitution of hegemony". IPW Working Paper No. 1/2007. Institut für Politikwissenschaft Universität Wien. Disponível em http://politikwissenschaft.univie.ac.at/fileadmin/user_upload/inst_politikwiss/IPW_Working_Papers/IP W-Working-Papers-01-2007-Brand.pdf. (acessado em 20 de janeiro de 2014) 
suposta emergência de um "Estado global", que estaria gradualmente alcançando mais e mais autonomia em relação aos Estados nacionais (como seria o caso de Hardt e Negri) ${ }^{34}$. Ao contrário, o autor sustenta que esse aparato mantém fortes laços com os Estados nacionais, "especialmente com aqueles que são potências, como os EUA".

A partir do conceito poulantziano de "condensação de segunda ordem", Brand vai defender a tese do "Estado internacionalizado" como uma "condensação de relações societais de forças de segunda ordem". Os aparatos de Estado internacional (international state apparatuses, ou INSTA, na sigla em inglês), como "dispositivos de poder numa rede transnacional", seriam partes de uma complexa rede, instável e assimetricamente estruturada, a qual é materializada em formas específicas. A fixação de diferentes conflitos sociais, assim como intergovernamentais, seria a principal forma de movimento das políticas internacionais.

A metáfora para a condensação de relações societais de forças de segunda ordem não se referiria a uma hierarquia do internacional sobre as políticas nacionais ou vice-versa. Ao contrário, o ponto é que interesses particulares nos Estados nacionais se condensam, dentro de relações específicas de forças, em políticas estatais, as quais seriam sempre integradas dentro de constelações de poder internacionais ("condensações de primeira ordem").

Os INSTA não seriam centralizados, embora organizados e institucionalizados em certas maneiras; eles seriam especializados e especificamente políticos, porque suas funções seriam tornadas permanentes através de leis e regras, assim como distribuídas através de diferentes áreas e formalmente separadas do poder econômico. Ao mesmo tempo, os INSTA possuiriam "sua própria densidade e poder de resistência" vis-à-vis os poderes societais globais.

A densidade seria também produzida pelo fato de que as formas e conteúdos das controvérsias políticas inseridas nos INSTA, de um lado, corresponderiam essencialmente às constelações de poder existentes a dado momento entre os países, classes, gêneros e grupos étnicos e, por outro lado, tornariam essas 
constelações perduráveis no tempo. As condições dos processos de negociação tensa, e a composição de regras e implementação de políticas seriam estabelecidos dentro dos INSTA. Desta maneira, formas de política são moldadas, assim como seletividades estruturais e estratégicas, e existiria uma determinação de prioridades e uma filtragem de medidas. Sob condições que estão dinamicamente mudando, seria possível, assim, determinar o caráter da transformação, de executar mudanças em canais regulares e então, promover hegemonia.

Os INSTA individuais, tanto organizações como acordos ou regimes, manteriam uma relação de mútuo suporte e complementação, mas às vezes até uma relação de competição, e, no total, elas permaneceriam em uma relação mutuamente assimétrica na forma de uma rede. As políticas internacionais, neste sentido, seriam elas mesmas um resultado das relações inerentes de forças e contradições nos aparatos internacionais. Os últimos constituiriam a estrutura material do Estado e seriam reproduzidas - também num nível internacional dentro do Estado. Ou seja: as tensões e contradições das diferentes forças seriam expressas por tensões e contradições dentro dos diferentes aparatos.

A coexistência de diferentes instituições, as quais seriam por vezes competentes ou feitas responsáveis para a mesma área, seria uma estratégia de poder adotada por atores políticos em atendimento a seus interesses. Atores estatais nacionais influentes poderiam mudar o terreno, por exemplo, no caso de que um problema seja inconvenientemente "politizado", por exemplo - esse processo é chamado de "mudança de fórum" (forum-shifting). Para Brand, na verdade, não existiria uma hegemonia internacional no sentido (neo)gramsciano, daí falar de uma "hegemonia fragmentada".

Não podemos, entretanto, terminar este ponto sem nos referirmos a um conhecido nome hoje desta matriz "neopoulantziana", o politólogo inglês Bob Jessop, autor de extensa obra acerca da teoria do Estado. Muito embora Jessop se posicione ao lado da teoria poulantziana, ele afirma também que Poulanztas teria caído numa espécie de "reducionismo de classe", vacilando na tentativa de antecipar 
mudanças decorrentes da internacionalização do capital. ${ }^{35}$

Em relação à análise da internacionalização do Estado, brevemente discutida por nós anteriormente, Jessop retoma os argumentos de Poulantzas contrários à idéia de que, decorrente desta internacionalização viria um superestado ou uma "supranacionalização" dos Estados. Não vamos repeti-los aqui. ${ }^{36} \mathrm{O}$ fato é que, diante daquelas análises, Jessop tece três comentários críticos. O primeiro seria que Poulantzas teria dedicado pouca atenção aos processos de trabalho, focalizando exclusivamente a relação entre propriedade econômica e posse, caindo assim num reducionismo de classe. Em segundo lugar, Poulantzas, ao discutir a autonomia relativa do Estado, teria caído num enfoque excessivamente funcionalista, limitandoa às tarefas de organizar as classes dominantes e desorganizando as dominadas, "derivando o poder efetivo do Estado da correlação mutável das forças políticas de classe". ${ }^{37}$

Em relação à análise empírica do imperialismo, Jessop argumenta que embora haja uma dominação do capital e do Estado norte-americanos, os capitais europeus e leste-asiáticos continuariam a competir com o norte-americano e agora os conflitos internos aos blocos de poder nacionais da Europa refletiriam "laços estruturais e conjunturais com o Leste asitático bem como com os capitais norteamericanos e com os demais capitais europeus."38

As demais transformações do Estado apontadas por Jessop estão mais ou menos apontadas em Gorg e como veremos também em Hirsch, não sendo necessário retomá-las aqui, sendo mais importante agora passar a exemplos mais concretos do que seriam estes processos.

35 JESSOP, Bob. "A globalização e o Estado Nacional". In. Crítica Marxista, São Paulo, Xamã, v. 1, tomo 7, p. 9-45, 1998. Nas palavras de Jessop, apesar de grandes avanços, "Poulantzas continuou preso à economia política marxista clássica. $E$ isto porque as suas análises tinham como premissas o papel em última instância determinante do modo de produção no que concerne a todos os aspectos da organização societal, a primazia da contradição fundamental entre capital e trabalho e o poder diretor da luta de classe proletária na transição para o socialismo." Idem, p. 12.

$36 \quad$ Idem, p. 16-21.

$37 \quad$ Idem, p. 26.

$38 \quad$ Idem, p. 26. "As formas através das quais a relativa superação da defasagem entre poder econômico e posse está sendo realizada são mais complexas, mais flexíveis, mais assemelhadas a uma rede e mais internacionais que aquelas antecipadas por Poulantzas durante a crise emergente do fordismo atlântico." Idem, p. 27. 


\section{Estudos de caso acerca da internacionalização do Estado: o MAI (Multilateral Agreement of Investment) e a Convenção sobre a Diversidade Biológica}

Localizamos dois interessantes estudos de caso que demonstram como se dá, na prática, o tão debatido processo de "internacionalização do Estado", o que talvez sirva para entender melhor de que tipo de fatos se está tratando. O primeiro é o estudo realizado pelo sociólogo americano Daniel Egan sobre o caso o Multilateral Agreement of Investment (MAl), tentativa fracassada de desenvolver no âmbito da OCDE um amplo acordo internacional que visava uma liberalização sem precedentes de investimentos. ${ }^{39} \mathrm{O}$ segundo, do já citado C. Gorg, ${ }^{40}$ é a Convention on Biological Diversity (CBD), (ou, Convenção sobre a Diversidade Biológica) que derivou diretamente da Rio 92 e existe até hoje. Comecemos pelo MAI.

Desde 1976 a Organização para a Cooperação e Desenvolvimento Econômico, OCDE, tinha estabelecido um set de padrões voluntários para o comportamento de multinacionais em países hospedeiros. Em 1995, ela chamou por um forte e amplo acordo de investimento que removeria restrições na movimentação global de capital. As negociações começaram em setembro de 1995 e seriam completadas em maio de 1997, mas este deadline foi adiado para maio de 1998 e depois para outubro do mesmo ano, quando os encontros de negociação de ministros da OCDE foram suspensas indefinidamente. O rascunho do MAI proibia discriminações contra investidores estrangeiros através do uso de tratamento nacional. Os Estados membros estariam, por exemplo, proibidos de expropriar ou nacionalizar investimentos estrangeiros, "ao menos não em bases discriminatórias".

Segundo Egan, o rascunho do MAl refletia uma estratégia legal e política dos maiores Estados capitalistas para separar o capital dos constrangimentos de accountability política disponíveis a forças populares ao nível do Estado-Nação, por mais limitados que pudessem ser. Ao invés de um processo determinado pela ascensão de uma classe capitalista transnacional, a internacionalização do Estado é

39 EGAN, Daniel. Global capitalism and the internationalization of the State: some lessons from the defeat of the Multilateral Agreement on Investment (MAI). Paper apresentado na International Conference on The Work of Karl Marx and Challenges for the XXI Century, Havana, Maio de 2003. Disponível na Biblioteca Virtual da Clacso, em: http://bibliotecavirtual.clacso.org.ar/ar/libros/cuba/if/marx/documentos/22/Global\%20capitalism \%20and\%20the\%20internationalization.pdf. (acessado em 17de novembro de 2014).

40 GORG, C. Op. Cit. 
vista por Egan como produto da agência de administradores estatais e seus aliados corporativos e profissionais.

Até aí, o MAl poderia parecer refletir o modelo do conceito de internacionalização do Estado dos neogramscianos, no sentido de expressar um consenso entre Estados capitalistas avançados para crescente liberalização de movimentação de capital, e isso preconizava certamente uma dramática mudança nas funções do Estado-Nação em direção à proteção e expansão do capital global. No entanto, o fracasso em criar um novo regime de investimento supranacional sugeriria que a internacionalização não é um processo inevitável. O descarrilhamento do MAI teria sido, para Egan, resultado de conflitos hegemônicos dentro do bloco histórico e entre o bloco histórico e as forças sociais subordinadas. Vejamos como.

A própria definição do fórum apropriado ao acordo gerou problemas desde o início. Como os países europeus tinham fortes bancadas parlamantares que se oporiam, cogitou-se inicialmente que as negociações fossem realizadas no âmbito da World Trade Organization (WTO), que tinha maior representação em número de países; mas este também poderia sofrer de países pobres que refutariam ou ao menos denunciariam a liberalização. Os EUA, que não tinham o mesmo problema de oposição política à liberalização institucionalizada, teriam então forçado a utilização da OCDE como o fórum adequado para o MAI.

Alguns países como Austrália e Canadá discordavam de cláusulas do acordo para proteger negócios nacionais de serem tomados em massa por compradores estrangeiros. A França finalmente se retira das negociações em outubro de 1998.

Embora o fato de que as negociações fossem secretas impedisse maiores demonstrações de oposição, em fevereiro de 1997 o rascunho foi vazado e postado na internet, o que fez com que a OCDE tivesse que considerar as posições de algumas ONGs internacionais como a Friends of the Earth, a Third World Network e a Public Citizen, ao menos informalmente, e fez com que se acrescentasse no rascunho do tratado expressões como "responsabilidade social corporativa" e "consistente com o desenvolvimento sustentável" - o que acabou se tornando motivo de deboche generalizado. 
Além disso, entre os maiores entusiastas do acordo (por exemplo a US Council for International Nusiness, a Union of Industrial and Empluyers Confederation of Europe, a International Chamber of Commerce e a japonesa Keidanren) começou a haver dúvidas se o acordo atingiria seus objetivos. Portanto, esses três tipos de conflitos - entre Estados membros da OCDE, entre OCDE e forças sociais subordinadas, e por fim entre a OCDE e importantes elementos do capital multinacional - revelaram a natureza contraditória do bloco hegemônico transnacional, demonstrando assim que a internacionalização do Estado, tal como compreendida pelo "materialismo histórico transnacional" não seria algo irresistível e sim um processo de embates contínuos.

O segundo estudo de caso, de autoria de C. Gorg, analisa as principais determinações do CDB, a Convenção sobre a Diversidade Biológica, fruto da Rio 92. Segundo Gorg, as transformações societais como as que ocorrem no que é chamado de transição ao "pós-fordismo" estão sempre conectadas com transformações de suas relações com o meio ambiente. No atual contexto, mais do que nunca, a procura pelo "ouro verde dos genes", direcionada ao controle e aplicação dos recursos genéticos, continuaria a ser uma das mais dinâmicas e importantes áreas de conflito na relação pós-fordista com a natureza. Para Gorg, o problema ambiental global e a chamada "perda de diversidade biológica", estariam fortemente conectados com este conflito sobre a apropriação dos recursos genéticos, principalmente porque a "diversidade da vida" representa aqui o input essencial, a matéria-prima das novas biotecnologias. Em contraste com esses elos entre "economia" e "ecologia", a perda de diversidade biológica estaria ainda largamente entendida somente como um problema ambiental global. Seguindo este entendimento, a CDB é vista como um exemplo claro de arquitetura de "governança global", principalmente por ter levado à formação de um regime ambiental internacional. Gorg demonstra o desenvolvimento de todos os processos característicos da "internacionalização do Estado" nas negociações da CDB. Senão, vejamos.

Primeiro, o enquadramento das negociações em compromissos sociais. A "modernização ecológica" ou "desenvolvimentismo verde" teria sua própria elite 
global, calcada na figura do "gerente de recursos global". Esta classe de gerentes de recursos globais consistiria em membros de governos, organizações internacionais como Banco Mundial e ONGs, bem representados também em esforços como a "Iniciativa de biocomércio" da UNCTAD, de 1997. Aqui, também, a chamada "privatização da política" tem lugar, pois através dessa iniciativa, estabeleceu-se que ONGs e outras companhias, trabalhando como intermediários, estão habilitadas a "ajudar" os países a estabelecer regras e material legal para criar mercados globais para os recursos genéticos - evidentemente, nada disso é feito de forma "desinteressada" ou neutra.

Paradoxalmente, segundo Gorg, junto com o fato de que não haveria "real" soberania, a validação legal da soberania nacional seria ao mesmo tempo importante para estabelecer mercados globais para recursos genéticos. Neste nível, não haveria contradição entre soberania nacional e internacionalização de regimes políticos. Mais do que isto: ambos aspectos da internacionalização do Estado - a crescente coordenação internacional e a transformação do Estados nacionais passam a ser compreendidas como pré-condição para a valorização dos recursos genéticos. Ambos seriam partes importantes da constituição da diversidade biológica como recurso para exploração capitalista, principalmente pelo interesse existente na busca por regras e procedimentos legais constituintes de mercados. Devido aos altos custos da pesquisa e desenvolvimento de novos produtos, a "indústria da Vida" estaria ela mesma interessada em segurança legal e de planejamento; o estabelecimento de leis, neste sentido, não seria necessariamente contrário ao interesse do capital. E, por outro lado, também existe a necessidade de proteção às relações capitalistas de propriedade numa área em que até então não existiam relações de propriedade. E para isto é imprescindível a força do Estado nacional.

A CBD, como todos os INSTA (ver item anterior) estaria permeada de conflitos e contradições; seria, portanto, um campo permanente de conflitos. Entre estes sistemas de regulação existe uma porção de tensões; duas delas são destacadas pelo autor: a questão da patenteabilidade dos recursos genéticos, e os direitos das populações tradicionais. Gorg analisa brevemente como estas duas tensões se deram na CDB, demonstrando assim que os aparelhos do "Estado internacional" não 
estão imunes a conflitos, muito embora, ao contrário do MAI, esse regime tenha se consolidado.

As perspectivas "neogramsciana" e "neopoulantziana" não são, no entanto, as únicas a pensarem o problema da internacionalização do Estado. Também uma vertente alemã, a partir de uma espécie de síntese de elementos teóricos de Gramsci, de Poulantzas e também da bastante heterogênea vertente "regulacionista" francesa, procurou dar uma interpretação original a este fenômeno.

\section{Joaquim Hirsch e os regulacionistas}

Para discutir a questão da internacionalização do Estado, Hirsch situa que a constituição histórica do moderno sistema de Estados - que como se sabe, se estabelece na chamada Paz de Westfalia - não se deu de forma isolada. No debate recente acerca da "globalização" e daquilo que alguns autores denominaram "Estado global", o autor afirma que uma pergunta central passou a ser: a existente multiplicidade de Estados é estrutural ao capitalismo, ou se constitui acontecimento histórico "casual"? ${ }^{41}$ Para responder a esta questão, formulou-se, por exemplo, a tese de que a ordem estatal seria crescentemente suplantada por complexas redes estatal-privadas, e, ao invés da direção hierárquica-burocrática, haveria "sistemas de negociação" com cada vez maior participação de atores estatais e não-estatais (naquilo que ficou conhecido como "governance" substituindo o "government"). ${ }^{42}$

De acordo com o balanço de Hirsch, de um lado estaria a idéia de que aquela "ordem de Westfália" estaria em dissolução, e consequentemente não restaria muito do Estado Nacional tal como o conhecemos. De outro lado, estaria a posição que reafirma o sistema nacional estatal, apenas com algumas modificações decorrentes da mera adaptação da estrutura estatal tradicional às novas condições técnicoeconômicas. Para Hirsch, ambas as respostas a este problema têm sido insuficientes, e muitas das análises apresentadas padecem por "generalizar tendências isoladas e omitir contradições", em sua maior parte, equívocos

41 HIRSCH, Joaquim. Teoria materialista do Estado. Rio de Janeiro: Revan, 2010. p.69.

$42 \quad$ Idem, p. 172. 
decorrentes de uma fraca teorização sobre o Estado.

Em suma, o autor tende a concordar com a idéia de que a multiplicidade de Estados "não caracteriza apenas uma fase histórica determinada, mas representa um traço básico da forma política capitalista e uma das condições essenciais de sua preservação e de seu desenvolvimento" ${ }^{43}$. Ressalva, porém, que é necessário distinguir entre Estado Nacional e Estado territorial isolado - distinção que no idioma inglês se faz entre "nation state" e "national state".

Cabe aqui uma citação mais completa acerca da argumentação de Hirsch.

\begin{abstract}
"O motivo para a multiplicidade de Estados representar um traço constitutivo do capitalismo, e não uma manifestação histórica casual, consiste em que as contradições e as oposições sociais presentes no modo de socialização capitalista, isto é, os antagonismos de classe e a concorrência, não apenas manifestam-se na 'separação' do Estado frente à sociedade, como também são simultaneamente produzidos pela concorrência entre os Estados. $O$ sistema de Estados é uma expressão estrutural das relações capitalistas de classe e de concorrência. Elas reproduzem nele e determinam seus conflitos e dinâmicas de desenvolvimento. Recordemos mais uma vez: a determinação formal do político expressa na 'autonomia relativa' do Estado permite que a sociedade capitalista, caracterizada por contradições e conflitos básicos, possa manter-se. Considerando o reverso, a 'separação' do Estado é a base decisiva do 'fetiche estatal', ou seja, da representação de que no Estado se corporifica uma 'vontade geral' colocada acima de relações sociais de desigualdade, de exploração e de domínio. O decisivo então é que a implantação e a preservação dessa forma pressupõem a delimitação de cada Estado, com suas relações de classe e seus compromissos institucionalizados, frente aos demais. Em um Estado global, isso não seria possível e o fetiche do Estado não poderia ser eficaz, fazendo com que faltasse uma base decisiva de legitimação das relações existentes. O argumento poderia indicar que um Estado capitalista mundial é abstratamente pensável, mas, por princípio, ele deveria colocar em questão a permanência do modo de produção e de socialização capitalista. $\mathrm{Na}$ realidade, existem condições estruturais e relações de força - concorrência e antagonismos de classe que tornam tal desenvolvimento altamente improvável." ${ }^{44}$
\end{abstract}

Outro efeito importante do sistema de Estados seria que, pelo sistema interestatal, os membros das classes em concorrência recíproca podem estabelecer oposições com as respectivas classes localizadas nos outros Estados. Disso decorre a possibilidade, muito concreta, da formação de coalizões que transcendam as classes. ${ }^{45} \mathrm{O}$ cerne da resposta de Hirsch à questão se relaciona com a distinção

$\begin{array}{ll}43 & \text { Idem, p. } 175 . \\ 44 & \text { Idem, p. 70-71. } \\ 45 & \text { Idem, p. 72. Grifo do autor. }\end{array}$


entre a forma política burguesa e a forma institucional que esta assume: os processos de transformação não implicariam no fim do Estado e do sistema interestatal, mas em uma nova configuração, a qual, embora preserve o traço fundamental da ordem capitalista, ganha contornos qualitativamente diferentes.

Toda a teoria de Hirsch está baseada nas teses regulacionistas de "regime de acumulação" e "modo de regulação" - o primeiro, entendido como o conjunto de técnicas de produção, organização do trabalho, formas de extração do mais-valor e relações entre os setores de produção; e o segundo, como a rede de instituições e normas políticas que regulam e permitem a reprodução do regime de acumulação. Nesse sentido, o Estado regula, mas ao mesmo tempo é objeto da regulação. Acumulação e regulação, na visão de Hirsch, formariam uma unidade contraditória, possuindo dinâmicas próprias. Dessa forma explica-se, por exemplo, a possibilidade de que o desenvolvimento de um novo regime de acumulação não mais corresponda a determinado modo de regulação levado pelo passado, como seria aliás o caso do fordismo e do pós-fordismo.

As "crises seculares" do capitalismo constituiriam os momentos nos quais se ativam mais fortemente as lutas ideológicas e nas quais se criam as condições para a ascensão de um ou outro projeto hegemônico. A crise dos anos 1970 teria constituído justamente um desses momentos. A relação entre essas duas dimensões, em esfera internacional, constituiria o que os regulacionistas chamam de "regulação internacional". O modo de regulação internacional do fordismo, por exemplo, estaria calcada nas instituições de Bretton Woods. ${ }^{46}$

Nesse sentido, a internacionalização dos Estados, entendida enquanto internacionalização do próprio aparelho de Estado, mas também como "diversificação dos níveis e das funções estatais de natureza sócio-espacial", ${ }^{47}$ seria conceito adequado para sintetizar esses processos de transformação, desde que entendido nesses marcos.

$46 \quad$ Em relação ao imperialismo, Hirsch pontua que "diferentemente da teoria clássica do imperialismo, da teoria do sistema-mundo, ou da teoria da dependência, o enfoque da regulação não conceitua o sistema global capitalista como uma relação espacial e temporal fixa de dominação e subordinação manejada desde um centro (...), mas o concebe como uma rede variável de contextos de acumulação e regulação nacional-regionais que se encontram e oposição entre si, mas estando ao mesmo tempo vinculados." Idem, p.124.

$47 \quad$ Idem, p. 175. 
As características básicas deste processo seriam, em primeiro lugar, a dependência ainda mais forte de cada aparelho estatal frente aos mercados internacionais de capital e de dinheiro, o que submete os Estados a uma rígida disciplina monetária. Em segundo lugar, a flexibilização do fluxo internacional de capital conduziria ao incremento da pressão sobre o Estado para condições cada vez mais otimizadas para a valorização. Em terceiro, a redução da capacidade de intervenção estatal, marcada tanto pela fragmentação sócio-espacial, com o aumento das disparidades regionais intra-estados, quanto pelo significado crescente dos entrelaçamentos econômicos que atravessam as fronteiras estatais. Quarto, uma tendência à "privatização da política", com a importância crescente dos atores privados tanto no plano da formulação da política quanto no plano de sua implementação. E quinto, a internacionalização de regulamentações políticas que superariam a capacidade dos Estados singulares, nas quais a perda do espaço de ação do Estado é compensada pela formação de blocos.

Por fim, estaria havendo o surgimento de uma "classe capitalista empresarial internacional", "composta pelos funcionários das empresas, pelo pessoal dos aparelhos estatais e organizações transnacionais, mas também por cientistas e representantes das organizações não-governamentais existentes" ${ }^{48}$. No entanto, para Hirsch, isso não significaria o surgimento de uma "classe capitalista transnacional", independente dos Estados, tal como aparece em parte da literatura aqui mencionada, pois "a relação concorrencial capitalista se reproduz no plano do sistema de Estados e das organizações internacionais sob novas formas, gerando conflitos permanentes". ${ }^{49}$

Desse modo, o capital continuaria dependendo essencialmente da atuação do Estado, mas agora se apoiaria de forma diferente nas estruturas dos Estados internacionalizados, que teriam, aliás, sua importância acentuada para proporcionar infra-estrutura social, técnica e econômica, para regular as relações de classe, para a legitimação das relações dominantes, para garantir certa coesão social e para limitar a circulação da força de trabalho.

48 Idem, p.178.

49 Idem, p. 179. 


\section{Considerações finais}

Vimos como algumas correntes críticas no campo das R.I., e das ciências sociais em geral, têm tratado do importante tema da internacionalização contemporânea do Estado Nacional. Procuramos localizar esse conjunto bastante heterogêneo de autores dentro de algumas correntes de pensamento que, de um ponto de vista crítico, têm se preocupado em teorizar e realizar estudos empíricos acerca desse complexo processo. Pudemos observar que todas essas correntes têm valiosas contribuições para pensar sobre o tema, mas também carregam lacunas ou inconsistências teóricas.

Os neogramscianos enfatizam a utilização de conceitos como hegemonia e bloco histórico para caracterizar a ascensão de uma fração de classe transnacional, que para eles estaria no centro do processo de internacionalização do Estado; já os neopoulantizanos reafirmam a importância dos Estados Nacionais, que teria na verdade aumentado, com esse processo. Ambos concordam, no entanto, não só com o uso do termo "internacionalização do Estado", mas que existe um processo complexo com relação às funções e ao papel dos Estados no sistema internacional que vem se desenvolvendo dos anos 1970 até o presente. Estaria esse problema já bem respondido pela literatura especializada? Até certo ponto muito já se avançou, mas ainda existem lacunas importantes neste debate, por exemplo com relação ao papel crescente de potências regionais. Isso de deve ao fato de que a maioria das teorias que tomaram o assunto por objeto tinha por foco os EUA e a Europa, sendo pouco trabalhadas as questões relativas ao chamado "Terceiro Mundo". Delinear como esse fenômeno é tratado teoricamente na literatura internacional é, no entanto, passo imprescindível para compreender qualquer caso específico, e esse foi nosso propósito nesse artigo.

\section{Referências bibliografias}

AYERS, Alison J. (ed.) Gramsci, Political Economy, and International Relations. Modern Princes and Naked Emperors. New York: Palgrave-Macmillan, 2008.

BIANCHI, A. "Estratégia do contratempo: notas para uma pesquisa sobre o conceito 
gramsciano de hegemonia". In. Cadernos Cemarx, Campinas, v. 4, p. 9-39, 2007. . O laboratório de Gramsci. Filosofia, História e Política. São Paulo:

Alameda, 2008. p.137-138.

BIELER \& MORTON (eds.). Images of Gramsci. London/New York: Routledge, 2006. BORBA DE SÁ, M.; GARCIA, A. S.; COX, R. W. "Overcoming the Blockage: an interview with Robert W. Cox". In. Estudos Internacionais: revista de relações internacionais, v. 1, p. 119-336, 2013.

COX, Robert. Production, Power and World Order: Social Forces in the Making of History. New York: Columbia University Press, 1987. . "Gramsci, hegemony and International Relations: an essay on method". Millenium, v. 12, n. 2, p. 162-175, 1983.

EGAN, Daniel. Global capitalism and the internationalization of the State: some lessons from the defeat of the Multilateral Agreement on Investment (MAl). Paper apresentado na International Conference on The Work of Karl Marx and Challenges for the XXI Century, Havana, Maio de 2003.

GARCIA, Ana Saggioro. A internacionalização de empresas brasileiras durante o governo Lula: uma análise crítica da relação entre capital e Estado no Brasil contemporâneo. Tese de doutorado em Relações Internacionais - IBRI. Pontifícia Universidade Católica do Rio de Janeiro, 2012.

GILL, Stephen (org.) Gramsci, Materialismo Histórico e Relações Internacionais. Rio de Janeiro: Edufrj, 2007.

GORG, C \& BRAND, U. "Global environmental politics and competition between nation-states. On the regulation of biological diversity". In: Review of International Political Economy, v. 7, n. 3, 2000.

GRAMSCl, Antonio. Cadernos do Cárcere. Volume 3. Rio de Janeiro: Civilização Brasileira, 2007.

HALL, John. Os Estados na História. Rio de Janeiro: Imago, 1992.

HALLIDAY, Fred. Repensando as relações internacionais. Porto Alegre: EdUFRGS, 1999.

HIRSCH, Joaquim. Teoria materialista do Estado. Rio de Janeiro: Revan, 2010.

HOBSBAWN, Eric. Era dos Extremos. O breve século XX (1914-1991). São Paulo, Companhia das Letras, 1995.

JESSOP, Bob. "A globalização e o Estado Nacional". In. Crítica Marxista, São Paulo, Xamã, v. 1, tomo 7, p. 9-45, 1998.

PANITCH \&GINDIN. The making of global capitalism. The Political Economy of American Empire. London/New York: Verso, 2012.

PASSOS, Rodrigo D. F. "Gramsci e a teoria crítica das relações internacionais". In Revista Novos Rumos, Vol. 50, n² 2, 2013.

POULANTZAS, Nicos. "The internationalization of capitalist relations and the NationState". In. Economy and Society. vol. 3, p. 145-79,1974.

O Estado, o poder, o socialismo. Rio de Janeiro: Graal, 2000.

SKLAR, Holly (org.) Trilateralism: managing dependence and democracy. Boston: South and Press, 1980.

SOUZA, H. O capital transnacional e o Estado. Petrópolis: Vozes, 1985. 